Article

\title{
Air Quality Planning and the Minimization of Negative Externalities
}

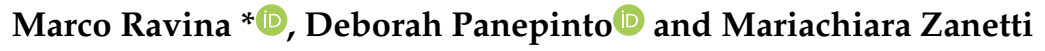 \\ DIATI (Department of Engineering for Environment, Land and Infrastructures), Politecnico di Torino, \\ 10129 Torino, Italy; deborah.panepinto@polito.it (D.P.); mariachiara.zanetti@polito.it (M.Z.) \\ * Correspondence: marco.ravina@polito.it; Tel.: +39-011-0907632
}

Received: 11 December 2018; Accepted: 7 January 2019; Published: 10 January 2019

\begin{abstract}
The minimization of negative externalities is a key aspect in the development of a circular and sustainable economic model. At the local scale, especially in urban areas, externalities are generated by the adverse impacts of air pollution on human health. Local air quality policies and plans often lack of considerations and instruments for the quantification and evaluation of external health costs. Support for decision-makers is needed, in particular during the implementation stage of air quality plans. Modelling tools based on the impact pathway approach can provide such support. In this paper, the implementation of health impacts and externalities analysis in air quality planning is evaluated. The state of the art in European member states is reported, considering whether and how health effects have been included in the planning schemes. The air quality plan of the Piemonte region in Italy is then considered. A case study is analyzed to evaluate a plan action, i.e., the development of the district heating system in the city of Turin. The DIATI (Dipartimento di Ingegneria dell'Ambiente, del Territorio e delle Infrastrutture) Dispersion and Externalities Model (DIDEM model) is applied to detect the scenario with the highest external cost reduction. This methodology results are extensible and adaptable to other actions and measures, as well as other local policies in Europe. The use of health externalities should be encouraged and integrated into the present methodology supporting air quality planning. Efforts should be addressed to quantify and minimize the overall uncertainty of the process.
\end{abstract}

Keywords: air quality planning; externalities; air pollution modelling; environmental policy

\section{Introduction}

The shift towards a sustainable and circular economy requires a constant and radical change in the use of available resources. The implementation of such a paradigm necessitates a complete understanding and description of the environmental consequences of various choices in the policy and planning process. In the re-definition of a sustainable economic model, the allocation and minimization of externalities represents a crucial aspect [1]. According to Pigou's definition, externalities or external costs occur wherever "a transaction between A and B has unwanted, positive or negative, consequences for a third party" [2]. In the evolution of an economic process, negative externalities may be generated whenever a natural resource is depleted, or harmful secondary flows (e.g., pollution) are produced.

Air pollution represents one of the most evident contributions to negative externalities, both at the global and the local scale. At the global scale, greenhouse gas emissions are contributing to climate change, bringing increasing losses of public money due to communities and territory protection and adaptation. At the local scale, several investigations showed that current levels of air pollutants observed in European cities are associated with health risks [3,4]. The adverse effects on human health translate to higher welfare costs for the community. In the way of supporting the optimal level of environmental control, air pollution external costs need to be estimated and minimized. Once 
reasonable estimates are available for the external costs, policy-makers will have the opportunity of internalizing these by taking actions on the relevant environmental taxes and charges.

Focusing on the regional and local scales, it follows from the above that the quantification of health damage external costs needs to be implemented in the environmental planning policies, to evaluate the contribution of different scenarios and mitigation measures. In the European Union, member states are required to design appropriate air quality plans (AQPs), defining possible emission reduction measures to improve air quality. The general structure and content of AQPs are regulated by the 2008 European Air Quality Directive (2008/50/EC) [5]. AQPs are developed at the national, regional and local levels, to address site-specific issues and sectors of intervention. AQPs need to be carefully designed with information and knowledge as accurately as possible, to reach a high level of acceptance and effectiveness among all stakeholders [6,7]. To this end, suitable supporting tools and approaches for data collection, analysis and assessment are needed. A wide range of modelling tools has been developed and applied in support of AQPs. The modelling methods range from simple scenario approaches, i.e., running the model with/without a specific emission source to quantify its impact on air quality levels [8,9], to more comprehensive ones like full cost-benefit analyses [10].

Methodologies for modelling the externalities associated with air pollution were first introduced by the ExternE research project series, financed by the European Union's Research Programmes [11,12]. ExternE introduced the impact pathway approach (IPA) to trace the specific impacts of pollutants. The methodology allows representing the health impacts of a scenario or a measure in different forms. If the incremental burden of disease is estimated, health effects may be represented, aggregating morbidity and mortality endpoints. Most notably, the concepts Disability-Adjusted Life Years (DALYs) and Quality-Adjusted Life Years (QALYs) are used for this purpose [13-15]. If a cost-benefit analysis (CBA) is performed, air-pollution-induced external costs are quantified.

The estimation of externalities associated to air pollution has been in some cases implemented in the models supporting the design process of AQPs $[16,17]$. Nevertheless, at present, aspects beyond air quality are not addressed or quantified in the vast majority of AQPs. Economic considerations, including the accounting of externalities, are in most cases neglected. This represents a disadvantage, as cost-benefit studies may facilitate the identification of those scenarios that provide largest welfare gains [18]. This lack of integration is particularly detected at the local scale, where effective and efficient indicators are needed for the implementation stage of AQPs.

The objective of this paper is to analyze the state of the art of AQPs in the EU region, with a particular focus on the health externalities of air pollution. In particular, this paper aims at evaluating and discussing the potential implementation of the model-based quantification of external costs as support for energy and environmental planning in urban areas. This analysis is concentrated on the implementation of local air quality action plans, where effective tools and indicators are needed to support decisions. To exemplify and strengthen the considerations reported, a case study is reported.

For any identified air quality issue and subsequent strategies considered, a transparent action plan enhances the chances of successful implementation. To this end, the following questions should be answered: what is the consideration of health externalities within the decision-making processes? How can health impact assessment (HIA) be effectively integrated into the AQP process? Could health externalities be employed as an efficient indicator in the evaluation of alternative scenarios?

This paper is organized as follows. Section 2 reports a state of the art of AQPs in the EU region. Section 3 reports the description and results of the case study. Section 4 reports a discussion. Section 5 reports some concluding remarks.

\section{Materials and Methods}

A significant contribution to the knowledge of the state of the art of AQPs in Europe was recently provided by the APPRAISAL EU FP7 project [19]. This project performed an overall review of the methodologies that EU countries used to define local and regional AQPs. A total of 59 contributions from 13 member states were analyzed. This review evidenced that integrated assessment modelling 
(IAM) methodologies are achieving increasing attention [9]. IAM tools integrate data on pollutant sources (emission inventories), the calculation of atmospheric concentrations and the estimation of human exposure, providing information on potential emission reduction measures and their respective implementation costs [20]. IAM can generally be divided into two main categories: (i) the scenario analysis [21], which consists in evaluating the impact on air quality of a set of mitigation measures; and (ii) the optimization analysis, where cost-efficient abatement measures are detected by minimizing or optimizing a set of objective functions or indicators. [22,23]. At today, few experiences involving IAM at the urban/local scale are reported $[20,24,25]$. Air quality models constitute one of the main components of IAM. The APPRAISAL database indicated a total of thirty-three different models used by local authorities. Regarding HIA, the APPRAISAL project reported that only 21 participants considered health impacts in the planning scheme. Of these, only 3 questionnaires have specifically expressed HIA as the main objective. (Figure 1). Among these implemented HIA, most studies use the current state of the art methodology as they refer to the World Health Organization (WHO) guidelines. The air pollutants considered most frequently in AQPs when health aspects are accounted for are particulate matter $\left(\mathrm{PM}_{10}\right.$ and $\left.\mathrm{PM}_{2.5}\right)$, nitrogen oxides $\left(\mathrm{NO}_{\mathrm{x}}\right)$ and ozone $\left(\mathrm{O}_{3}\right)$. Only 9 of the studies considered included the monetization of health effects.

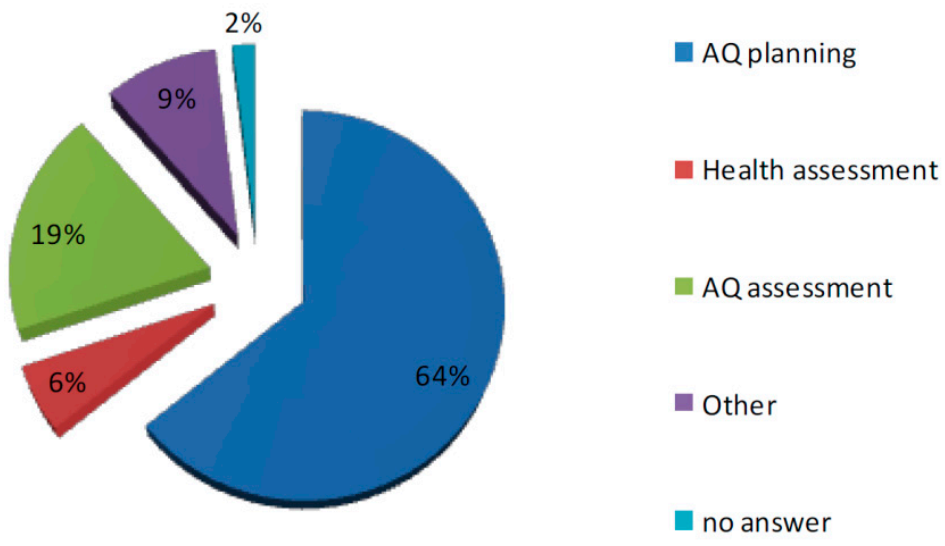

Figure 1. The main objective of Air Quality Plans expressed in the APPRAISAL project surveys [19].

The APPRAISAL project showed that, at present, modelling tools have addressed air quality assessment issues including dispersion and chemistry, but have not yet been integrated with other health indicators. HIA is recommended to be part of integrated assessment tools [26]. Quantification of health effects and costs in HIA is particularly important to support decision-makers to distinguish between the details and the main issues that need to be addressed [22].

The Air Implementation Pilot project, agreed by the European Commission and the European Environmental Agency [27], provided a better understanding of what cities need in order to better implement EU air quality legislation. A set of eight European cities was selected and invited to join the project. The results showed great diversity in the types of policies that the cities said they needed. The city experts reported several major challenges encountered when implementing air quality measures. These challenges were technological, cultural, legal, political, and economic. Public opposition was also considered to be a significant challenge and was visible in the difficulty of modifying the public's perception of a given environmental problem (e.g., climate change versus air quality) or solution (e.g., biomass burning reduces $\mathrm{CO}_{2}$ emissions but increases particulate matter emissions). Political realities also constitute a challenge, in the sense that air quality does not always rank very high on political agendas. Other challenges raised by the cities included the difficulty in promoting air quality improvement as an opportunity for economic growth.

Focusing on existing HIA modelling tools, Anenberg et al. [28] published a review article where 12 multinational air pollution HIA tools were analyzed and compared. Detailed air quality models, i.e., those accounting for the complex atmospheric chemistry and transport governing air pollution, 
were suggested for the implementation of HIA at the local scale. The DIDEM model [29] is considered in this study. Other examples include the Ecosense model [30,31], the Economic Valuation of Air pollution model (EVA) [32], the Urban Scale Integrated Assessment Model (USIAM) [33] and the (air quality modelling in urban regions using an optimal resolution approach (AURORA) modelling system [34]. Ecosense uses the Windrose Trajectory Model (WTM) [35] for estimating pollutant dispersion. The model assumes a constant average wind speed and the trajectories of emission transport are assumed to run along straight lines. EVA implements a non-linear Eulerian air pollution model, which comprises a standard local Gaussian plume model (Operational Meteorological air quality model, OML) [36] and the regional Eulerian model Danish Eulerian Hemispheric Model (DEHM) [37]. The USIAM is an integrated assessment tool developed to quantify the primary $\mathrm{PM}_{10}$ contribution, requiring the integration of information on the sources and pollution imported into the city, atmospheric dispersion and resulting concentrations relative to air quality standards, and costs and benefits of different options for emission reduction. The AURORA system also consists of various modules (e.g., health effects, economic aspects, scenario module, and European regulation) based on the ExternE methodology [38].

Existing tools can be practically applied in an integrated assessment of air quality, not only to consider compliance to the concentration limits, but also to efficiently take into account internal and external costs (e.g., health damage costs) of different available abatement options [39]. The biggest task when implementing such a comprehensive IAM is the quantification and evaluation of the overall uncertainty associated with the modelling chain.

\subsection{Air Quality Planning in the Piemonte Region, Italy}

The Piemonte region is in a strategic position in the north-west of Italy, linking Northern Europe with the Mediterranean Basin. The resident population in 2013 was 4,436,798 inhabitants (7.3\% of the national population), distributed in 1206 municipalities in a total area of about $25,400 \mathrm{~km}^{2}$ (corresponding to about $8.4 \%$ of the Italian territory). The population density is 175 inhabitants per $\mathrm{km}^{2}$. The gross domestic product (GDP) amounts to $8 \%$ of the national GDP.

Piemonte is surrounded by the Alps on three sides and more than $40 \%$ of its surface is mountainous, entailing an absence of wind that could contribute to reducing pollution. Past trends and future projections of climate models indicate an increase in the average temperature of around $1.5^{\circ} \mathrm{C}$ in the last 60 years, changes in distribution of seasonal precipitation, an increase of frequency and intensity of extreme weather events (like waves of heat, floods and droughts) and a decrease of snow and ice cover. In 2010, greenhouse gas (GHG) emissions were estimated equal to 31,433,830 t of $\mathrm{CO}_{2 \text { eq }}(7.05 \mathrm{t}$ of $\mathrm{CO}_{2 \text { eq }}$ per capita). The sectors that most contribute to GHG emissions are, in order of importance, transports, residential, agriculture, and industry. The Regional Environmental Protection Agency indicated that in 2011, an excess of $9 \%$ of mortality was detected due to anomalous weather conditions. This increase of mortality resulted highly correlated with the health stress index indicator [40]. Road transport is also responsible for the main emission of nitrogen oxides and particulate matter (Figure 2).
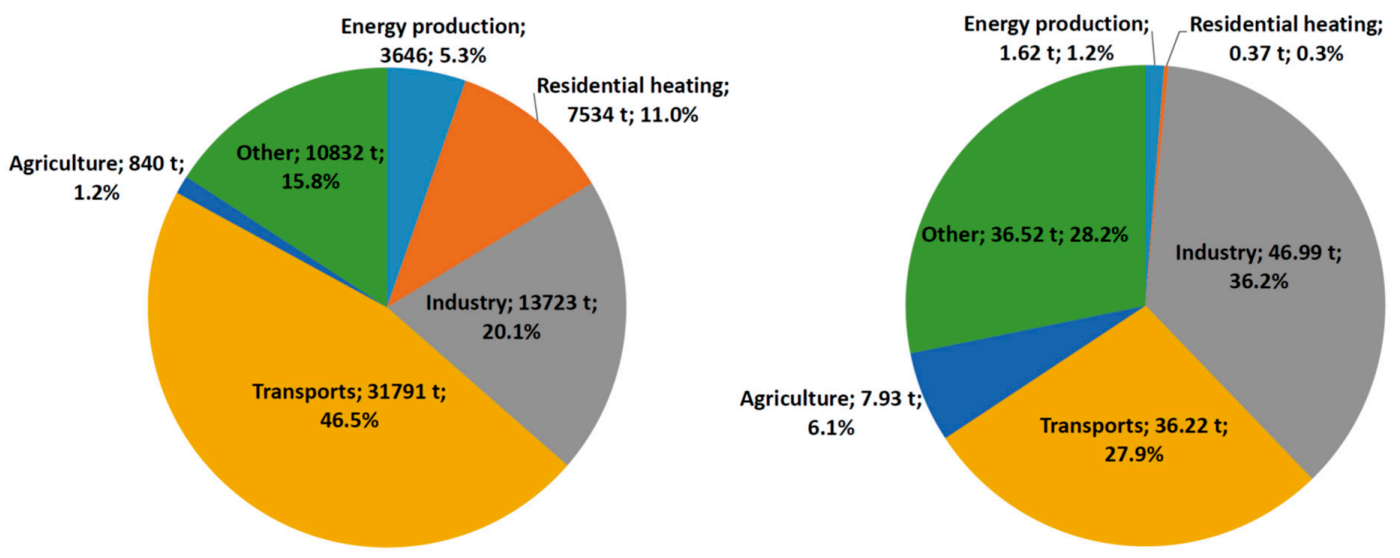

Figure 2. Emissions of $\mathrm{NO}_{\mathrm{x}}$ (left) and $\mathrm{PM}_{2.5}$ (right) by sector in the Piemonte region in 2013 [41]. 
Among the policy measures already in place, the reduction of emission from the residential sector through the development of large district heating networks is one of the most significant interventions in the metropolitan area of Turin, the region's capital city. Other measures include the transport sector: one underground line was completed in 2006, and a project for a second line is ongoing; an all-year ban of the most pollutant vehicles and Low-Emission Zones (LEZs) in all cities of the region have also been implemented. In the last 15 years, around $250 \mathrm{M} €$ of public money were spent in air quality-related initiatives, mainly for interventions in energy efficiency and renewable energies and for the improvement of regional public transport (such as replacing older buses with Euro V/VI vehicles).

In transposition of European Directives, the Piemonte region is currently implementing an update of energy and environmental plans. In 2015, with the subscription of the Under2Mou protocol [42], Piemonte's administration started to implement the European and national guidelines on sustainable development strategies and adaptation to climate change. By subscribing the Under2Mou protocol, the Piemonte region assumes the intention of reduction by $80 \%$ GHG emission within 2050, compared to 1990 levels. Regarding the reduction of local air pollution, the general objective is achieving target or limit values in the shortest possible time, compatible with the needs of the territory and taking into account the current socio-economic context. This general strategy is mainly reflected in three main documents, which are currently under public consultation: the Energy and Environmental Plan (in Italian, Piano Energetico Ambientale Regionale, PEAR), the Transport and Mobility Plan (in Italian, Piano Regionale dei Trasporti e della Mobilità, PRMT) and the Air Quality Plan (in Italian, Piano Regionale della Qualità dell'Aria, PRQA). Although these documents are strongly inter-connected, this paper focuses on the latter, as it directly deals with the objective of the study.

Piemonte's AQP (or PRQA) [43], in compliance with community, national and regional legislation, establishes general objectives, purposes and addresses for the identification and implementation of the actions and measures for the improvement or maintenance of the air quality in the region. PRQA was designed following a scenario analysis approach. Future trend scenarios were developed starting from the baseline scenario at 2010, modelling technological and behavioral developments on the territory. Three different scenarios were elaborated in the plan:

- the baseline scenario for the reference year 2010;

- the scenario at 2030, current legislation (the CLE scenario);

- the Plan scenario at 2030, in which the application of all the measures and actions foreseen in the PRQA proposal were evaluated (the Plan scenario).

The Greenhouse Gas-Air Pollution Interactions and Synergies model (GAINS), a tool developed at the European level by the International Institute for Applied Systems Analysis (IIASA) [44], was used for the calculations. The GAINS model integrates:

- the expected evolution of energy consumption and production activities;

- the control measures envisaged by CLE;

- the complex of actions foreseen by Piemonte's regional regulations.

The measures that were considered in the PRQA are reported in Table 1. These were divided into four areas of intervention: mobility, energy, industry and agriculture. A priority scale was defined inside each sector, based on the effectiveness of the measures, i.e., the amount of reduction of the various pollutants with respect to a baseline scenario. The estimated pollutant reduction of each measure was reduced by a factor keeping into account the degree of diffusion within the emissive sector involved. The results of the Plan scenario indicate significant emission reductions with respect to the trend CLE scenario: $37 \%$ less of particulate matter (PM), $16 \%$ less of $\mathrm{NO}_{\mathrm{x}}$ and $20 \%$ less of $\mathrm{NH}_{3}$. 
Table 1. Measures and actions implemented in Piemonte's AQP.

\begin{tabular}{|c|c|}
\hline Sector & Action/Measure \\
\hline \multirow[t]{17}{*}{ Mobility } & Remodelling of fuel excises \\
\hline & Limitation of diesel vehicles circulation \\
\hline & Electrification of railways \\
\hline & Development of local railways \\
\hline & Development of underground lines \\
\hline & Renovation of public transports \\
\hline & Introduction of a congestion charge \\
\hline & Management of low-emission zones \\
\hline & Promotion of teleworking \\
\hline & Development of bike lanes \\
\hline & Improvement of electric car sharing \\
\hline & Development of intelligent transport systems (ITS) \\
\hline & Mobility management \\
\hline & Extension of low-traffic zones and pedestrian ways \\
\hline & Improvement of urban logistics \\
\hline & Development of ticketing \& users loyalty \\
\hline & Parking management \\
\hline \multirow[t]{9}{*}{ Energy } & Energy storage in Alpine basins \\
\hline & Residential buildings refurbishment \\
\hline & Building renovation \\
\hline & Efficiency improvement of thermal units \\
\hline & Regulation of the use of biomass for heating purposes \\
\hline & Promotion of non-combustion renewable installations \\
\hline & Promotion of small renewable installations in buildings \\
\hline & Information on energy saving \\
\hline & District heating improvement \\
\hline \multirow[t]{2}{*}{ Industry } & Application of Best Available Technologies (BATs) to industrial processes \\
\hline & Reduction of volatile organic carbon (VOC) emissions \\
\hline \multirow[t]{5}{*}{ Agriculture } & Reduction of diffuse dust emissions \\
\hline & Support to low-ammonia emission agricultural practices \\
\hline & Reduction of ammonia emission from the zootechnical sector \\
\hline & Urban forestry compensation activities \\
\hline & Limitation of combustion of agricultural residues \\
\hline
\end{tabular}

The emission scenarios at 2030 (CLE and Plan) were used to estimate the resulting air quality status. This phase was developed by the Regional Agency for Environmental Protection (ARPA Piemonte), using a modelling chain based on the application of Eulerian chemical transport models (CTMs). The modelling chain was composed by the following modules: a meteorological interface module (MINERVE wind field model and SURFPRO3) [45,46], an emissions module (Emission Manager, EMMA) [45,46] and a CTM (Flexible Air Quality Regional Model, FARM) [46]), able to reconstruct three-dimensional fields of concentrations of the different chemical species. Furthermore, to identify the contribution of the different sectors to total emissions, a source apportionment was implemented. A specific model was used, based on the 3D sensitivity runs methodology /brute force method [47]. This method involves the realization of a reference simulation (base case) and an appropriate number of sensitivity simulations, one for each emissive sector to be analyzed.

Health impacts of air pollution were treated in a separate chapter of the PRQA. In this chapter, the methodology adopted in a previous project called VIIAS (in Italian, Valutazione Integrata dell'Impatto dell'Inquinamento atmosferico sull'Ambiente e sulla Salute; [48]) was applied to the CLE and Plan scenarios at 2030. The methodology of the VIIAS project considered the CRFs reported by the WHO for the long-term exposure to $\mathrm{PM}_{2.5}$ and $\mathrm{NO}_{2}$ of population aged over 30. Local specific population data and mortality background rates were used in this study. The results, in terms of 
premature deaths and years of life lost (YOLL) estimation, are reported in Table 2. These results show a significant reduction in mortality and morbidity.

Table 2. Estimation of change in mortality and YOLL consequent to the application of Piemonte's AQP [43].

\begin{tabular}{|c|c|c|c|c|c|}
\hline Pollutar & Cause of Death & Parameter & 2010 & 2030 CLE & 2030 Plan \\
\hline \multirow{9}{*}{$\mathbf{P M}_{2.5}$} & & Exposition $^{1}$ & 27.3 & 20.2 & 15.7 \\
\hline & \multirow[b]{2}{*}{ Natural causes } & Attributable cases & 4595 & 2822 & 1630 \\
\hline & & YOLL & 47,256 & 29,014 & 16,716 \\
\hline & \multirow{2}{*}{ Cardiovascular diseases } & Attributable cases & 2401 & 1497 & 875 \\
\hline & & YOLL & 20,084 & 12,514 & 7292 \\
\hline & \multirow{2}{*}{ Respiratory system diseases } & Attributable cases & 470 & 296 & 173 \\
\hline & & YOLL & 3744 & 2353 & 1374 \\
\hline & \multirow{2}{*}{ Trachea, bronchus, lung cancer } & Attributable cases & 345 & 214 & 125 \\
\hline & & YOLL & 5061 & 3143 & 1827 \\
\hline \multirow{3}{*}{$\mathrm{NO}_{x}$} & & Exposition $^{1}$ & 30.7 & 20.9 & 16.9 \\
\hline & \multirow{2}{*}{ Natural causes } & Attributable cases & 267 & 0 & 0 \\
\hline & & YOLL & 2890 & 0 & 0 \\
\hline
\end{tabular}

${ }^{1}$ Population-weighted average concentration $\left(\mu \mathrm{g} / \mathrm{m}^{3}\right)$.

The monitoring phase of the plan was based on two types of indicators:

- "status" indicators, expressed as absolute or relative quantities, used to evaluate the air quality status with respect to the regulation limits;

- " "performance" indicators, i.e., indicators that measure the degree of achievement of the objectives in absolute terms (effectiveness) and in relation to the resources used (efficiency).

\subsection{Critical Analysis of Piemonte's AQP}

The draft of Piemonte's AQP was recently submitted to the strategic environmental impact assessment procedure and the related public consultancy phase, according to Directive 2001/42/EC and national transcription. The same draft was also submitted to several experts in the field. The document received positive feedbacks, confirming the general adequacy of the content and methodology to the current state of the art. Nevertheless, in view of continuous improvement, a number of considerations should be reported. The first concerns the methodology of estimation of emission reduction. In Annex A of the PRQA, the measures reported in Table 1 were described in detail. A potential pollutant emission reduction was associated with each measure. The method of quantification and the assumptions at the basis of such emission reduction results are not always clear. In addition, the potential pollutant reduction was not quantified for all actions considered in the plan. The second consideration concerns the implementation phase of the plan. Unlike other region's AQP, the PRQA reports no information on the implementation phase, nor is a list of implementation rules reported in the final draft of the plan.

Translating policy plans into action has been observed to be a critical step in the achievement of an objective or strategy, not only in the environmental field [49]. This step requires a deepening of the technical details, timing, and location of single measures. Regional plans must be adopted by local administrations and municipalities, integrated into the local structure and accepted at all social levels. The evaluations reported in the plan, e.g., the reduction of pollutant concentration associated with actions, must thus be revised and elaborated at a higher spatial and temporal resolution. For air quality, this means integrating regional scale modelling with local-scale dispersion models. For HIA, this means characterizing single measures in terms of health effects and costs, based on a detailed distribution of pollutant concentrations and citizens' exposure.

In Piemonte's AQP, an HIA was calculated only on the aggregated results of the scenario analysis. This, of course, constitutes useful information in support and validation of the whole plan, as it reflects 
the positive feedback on citizens' welfare brought by the improvement of air quality. On the other hand, the authors believe that the effectiveness of HIA could be further improved by downscaling the analysis to a single (or groups of) measures and actions. This could bring valuable support to the definition of a priority scale of the interventions. The idea, as already mentioned, is using health externalities as an indicator of effectiveness. The authors also suggest that the estimated health effects should be translated to corresponding monetary units. The definition of health externalities would, of course, give significant support to the monitoring phase of the plan, when cost-benefit or cost-effectiveness analysis could be implemented. The case study described in the following aims at exemplifying these considerations.

\section{Case Study Definition and Results}

The measure implemented in Piemonte's AQP considered in this study is the improvement of the district heating $(\mathrm{DH})$ system in the municipality of Turin, identified in the plan by the code EE.04. $\mathrm{DH}$ is a technology used for supplying a town district or a complete town with the heat generated by large combined heat and power (CHP) plants. DH powered by CHP plants is an increasingly popular solution to meet the thermal energy needs in urban areas [50,51]. The project of Turin's DH network started in 1982 and progressively covered most of the urban area. The residential volume currently served amounts to about 60 million $\mathrm{m}^{3}$. The length of the network amounts to around $527 \mathrm{~km}$ of pipelines and is one of the most extended in Europe. Turin's DH network is currently powered by a system of two large combined cycle CHP plants fuelled by natural gas (named Turin North (TON), and Turin South (TOS)). A set of four integration and reserve boilers completes the system. For more information about the actual network structure and operating mode, refer to Ravina et al. [52].

In this study, a scenario analysis was performed on the TON and the TOS plants. The TON plant entered into operation in 2012. It is composed of a combined cycle unit having a total nominal power of $400 \mathrm{MW}_{\mathrm{e}}$ and $220 \mathrm{MW}_{\mathrm{th}}$, and three backup boilers having $339 \mathrm{MW}_{\text {th }}$ of total nominal power. Net electricity and thermal energy production in 2016 were $2070 \mathrm{GWh}_{\mathrm{e}}$ and $956 \mathrm{MW}_{\mathrm{th}}$, respectively. Total fuel consumption was $4.36 \times 10^{8} \mathrm{Sm}^{3}$. The emission stack of the system is $60 \mathrm{~m}$ high. Total emissions of $\mathrm{NO}_{\mathrm{x}}$ and $\mathrm{PM}_{2.5}$ in 2016 were $104.9 \mathrm{t}$ and $2.8 \mathrm{t}$, respectively (Table 3). The TOS plant was initially built in 1954 , and then subject to several revamping interventions. It is composed of two combined cycle units having a total nominal power of $778 \mathrm{MW}_{\mathrm{e}}$ and $520 \mathrm{MW}_{\mathrm{th}}$, and three backup boilers having $141 \mathrm{MW}_{\text {th }}$ of total nominal power. Net electricity and thermal energy production in 2016 were $2970 \mathrm{GWh}_{\mathrm{e}}$ and $1156 \mathrm{MW}_{\text {th }}$, respectively. Total fuel consumption was $6.024 \times 10^{8} \mathrm{Sm}^{3}$. The emission stack of the system is $70 \mathrm{~m}$ high. In 2014, during the last revamping, the plant was equipped with an advanced selective catalytic reduction system for the abatement of $\mathrm{NO}_{\mathrm{x}}$. Total emissions of $\mathrm{NO}_{\mathrm{x}}$ and $\mathrm{PM}_{2.5}$ in 2016 were $216.6 \mathrm{t}$ and $13.2 \mathrm{t}$, respectively (Table 3 ).

Table 3. Energy production and emissions of Turin's district heating system power plants.

\begin{tabular}{cccc}
\hline & TON $^{\mathbf{1}}$ Plant & TOS $^{2}$ Plant (Present) & TOS Plant (Scenario 1) \\
\hline Net electricity production $(\mathrm{GWh})^{3}$ & 2070 & 2970 & 2970 \\
Net thermal energy production $\left(\mathrm{GWh}_{\mathrm{th}}\right)^{4}$ & 956 & 1156 & 1156 \\
Fuel consumption $\left(\mathrm{Sm}^{3}\right)$ & $4.36 \times 10^{8}$ & $6.024 \times 10^{8}$ & $4.572 \times 10^{8}$ \\
$\mathrm{CO}_{2}$ emission $(\mathrm{kt})^{5}$ & 820.2 & 1133.1 & 859.9 \\
$\mathrm{NO}_{\mathrm{x}}$ emission $(\mathrm{t})^{6}$ & 104.9 & 216.6 & 147.8 \\
$\mathrm{PM}_{2.5}$ emission $(\mathrm{t})^{7}$ & 2.8 & 13.2 & 9.0 \\
\hline
\end{tabular}

${ }^{1}$ TON, Turin North plant; ${ }^{2}$ TOS, Turin South plant; ${ }^{3} \mathrm{GWh}_{\mathrm{e}}$, Gigawatt hours of electricity; ${ }^{4} \mathrm{GWh}_{\mathrm{th}}, \mathrm{Gigawatt}$ hours of thermal energy; ${ }^{5} \mathrm{CO}_{2}$, carbon dioxide; ${ }^{6} \mathrm{NO}_{\mathrm{x}}$, nitrogen oxides; ${ }^{7} \mathrm{PM}_{2.5}$, particulate matter $<2.5 \mu \mathrm{m}$.

Integrated HIA and calculation of health externalities were applied to two different scenarios on the TON and TOS plants, which were compared with the present operating configuration. In the first scenario (Scenario 1), an improvement of the overall energy efficiency of the TOS plant was assumed. Current best available technologies (BATs) conclusions on the associated energy efficiency level of 
combined cycle CHP plants indicate a net total fuel utilization between $65 \%$ and $95 \%$ [53]. At present, the TOS plant fulfills this recommendation, as in the year 2016 the plant achieved a total fuel utilization of $72 \%$. Scenario 1 analyses the (hypothetical) effects of further increasing the total fuel utilization to the maximum reference value, i.e., $95 \%$ (Table 3).

In the second scenario (Scenario 2), a relocation of TON and TOS plants was compared to the present situation, leaving the present plant emission factors unchanged with respect to the present. In Scenario 2, the TON plant was moved to approximately $8 \mathrm{~km}$ eastwards. The TOS plant was relocated to a dismissed industrial site, southwest of the actual position, at a distance of approximately $4.5 \mathrm{~km}$.

The authors point out that these scenarios are based solely on assumptions to be used as an example. Any further technical consideration of the real economic feasibility of the investment is not envisaged in this case.

The DIATI Dispersion and Externalities Model (DIDEM) developed by Turin Polytechnic was used in support of this scenario analysis. The DIDEM model [29], links the simulation of pollutants dispersion with the California Puff model (CALPUFF) or the SPRAY model $[45,46,54]$ to the concentration-exposure-response functions provided by latest WHO recommendations $[55,56]$. DIDEM calculates the spatial-distributed delta-external costs for each of the 14 health endpoints considered by the WHO methodology. The range of overall delta-external costs is calculated following the recommendations on the level of confidence and additional effects reported in the documentation of the Health Risks of Air Pollution in Europe (HRAPIE) project [55]. This methodology considers two different groups of pollutant-outcome pairs: Group $A^{*}$, i.e., pollutant-outcome pairs for which enough data are available to enable reliable quantification of effects; and Group B* i.e., pollutant-outcome pairs for which there is more uncertainty about the precision of the data used for quantification of effects. Monetary values implemented in the model are derived from the recent updates issued for the EU Clean Air Package [57]. More information on the methodological framework supporting the model can be found in [29].

$\mathrm{NO}_{\mathrm{x}}$ and $\mathrm{PM}$ emissions were studied for a 1-year period. The latest available (related to 2016) power units' emission flow rates were available with hourly temporal resolution. The meteorological input datasets collected in 2015 were used since sufficiently accurate and complete datasets were not available for 2016. SPRAY lagrangian particle dispersion model was used for the simulations. Geophysical and meteorological data input in SPRAY was obtained from the Regional Agency for Environmental Protection of the Piedmont Region (ARPA). Weather and orographic data covered a domain of $40 \times 40 \mathrm{~km}^{2}$ with a horizontal resolution of $200 \mathrm{~m}$. The same grid represented also the modelling domain. For more information about the methodology of analysis, refer to Ravina et al. [52,58].

Results

The results show that changes in power stations management and location may affect the incidence and costs of health impacts over the studied area.

The present (year 2016) $\mathrm{NO}_{x}$ and $\mathrm{PM}_{2.5}$ ground-level concentrations (annual average) resulting from SPRAY simulations are reported in Figures 3 and 4, respectively. Average $\mathrm{NO}_{\mathrm{x}}$ concentration over the urban area of Turin is between 0.2 and $1.4 \mu \mathrm{g} / \mathrm{m}^{3}$. The average $\mathrm{PM}_{2.5}$ concentration is lower than $\mathrm{NO}_{\mathrm{x}}$, due to the low PM emission potential of natural gas. Nevertheless, the influence of $\mathrm{PM}_{2.5}$ on the health effects is not negligible, as no threshold concentration is supposed for CRFs.

The average $\mathrm{NO}_{x}$ ground-level concentrations resulting from simulations of Scenario 1 and Scenario 2 are reported in Figures 5 and 6, respectively. In Scenario 1 (Figure 5), a lower emission rate corresponds to a lower concentration than the present (between 0.1 and $0.9 \mu \mathrm{g} / \mathrm{m}^{3}$ ). In Scenario 2 (Figure 6), the different locations of TON and TOS plants generate different spatial distributions of concentrations, while the range of magnitude remains unchanged. Figure 6 shows that the maximum average concentration is removed from the city centre, towards less populated areas. This, in turn, has an effect on health impacts and externalities results. 


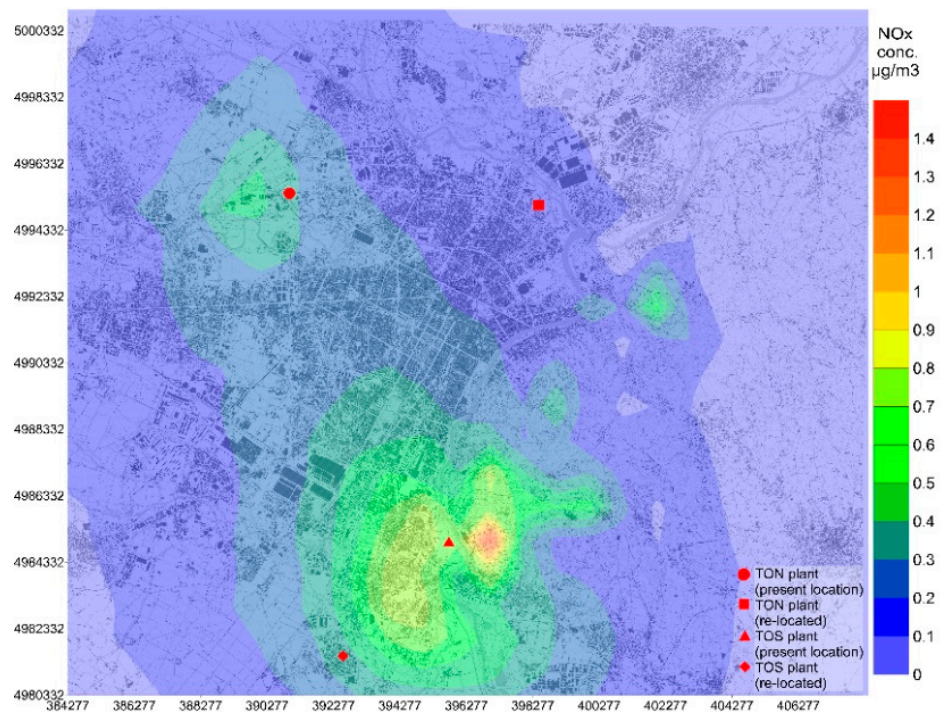

Figure 3. $\mathrm{NO}_{\mathrm{x}}$ concentration generated by Turin's DH system power plants (1-h annual average, base case).

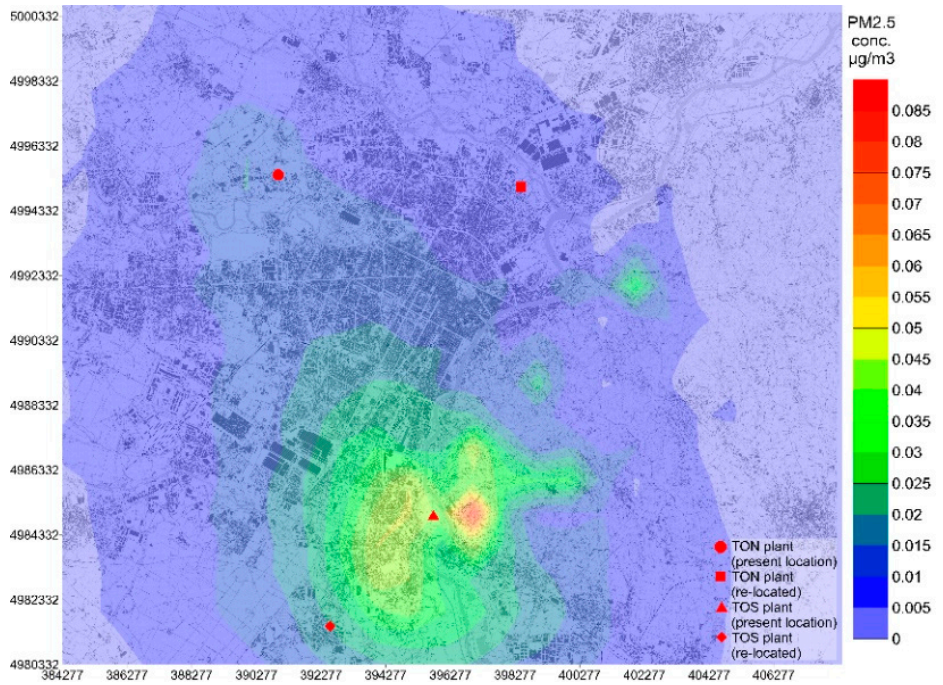

Figure 4. $\mathrm{PM}_{2.5}$ concentration generated by Turin's DH system power plants (1-h annual average, base case).

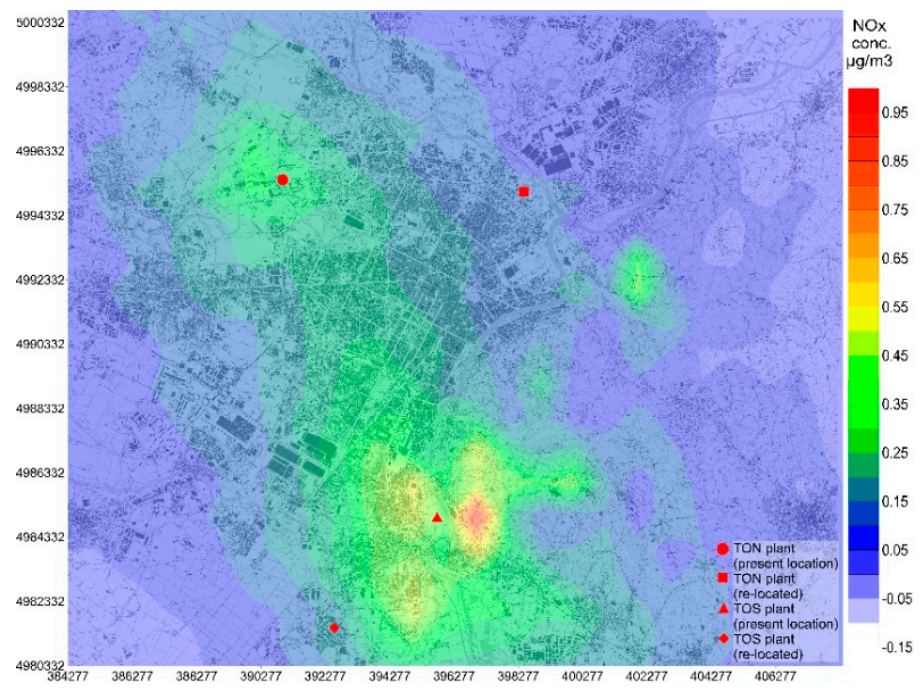

Figure 5. $\mathrm{NO}_{\mathrm{x}}$ concentration generated by Turin's DH system power plants (1-h annual average, Scenario 1). 


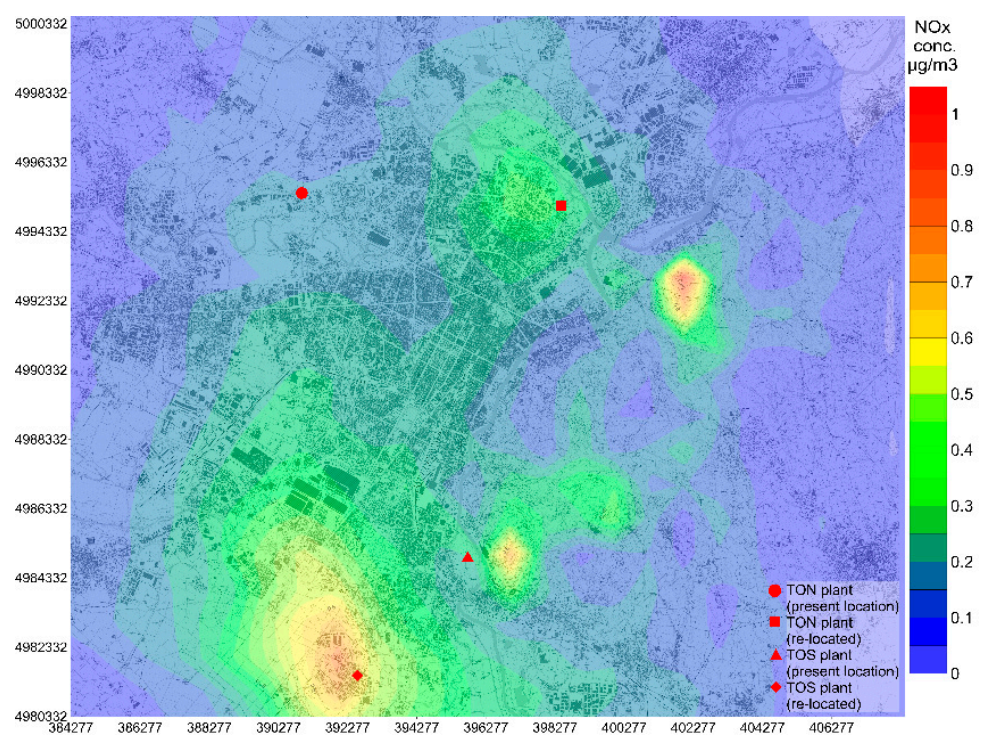

Figure 6. $\mathrm{NO}_{\mathrm{x}}$ concentration generated by Turin's DH system power plants (1-h annual average, Scenario 2).

The delta-external health costs resulting from simulations of Scenario 1 and Scenario 2 with the DIDEM model are reported in Figures 7 and 8, respectively. The difference with respect to the present situation is reported in these figures. In Scenario 1, a general cost reduction is obtained on the whole urban area. This reduction results marked in the central and southern areas of the city, where the combined effect of higher population density and higher concentration reduction is observed. In Scenario 2, the results are differentiated, depending on the area of the city considered. A cost reduction is observed on the majority of the urban centre, in particular in the central and southern areas. Conversely, an increase in costs is detected in the northern districts, in particular in the north-eastern area, where the TON plant is assumed to be relocated.

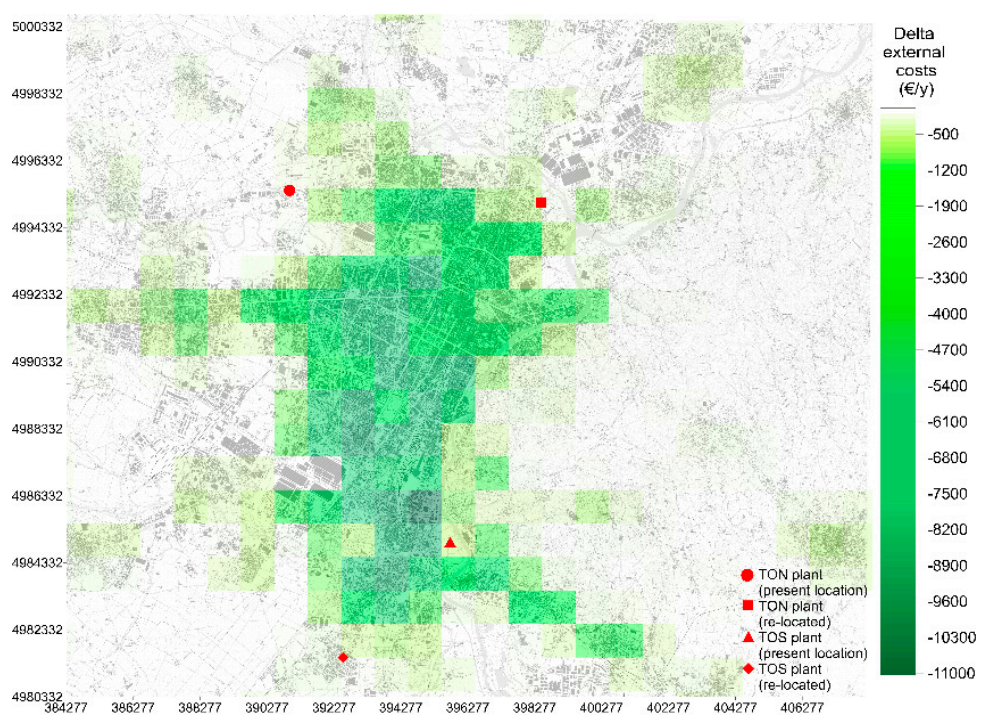

Figure 7. Distribution of delta-external costs between the base case and Scenario 1.

Table 4 shows the total difference of delta-external costs over the modelling domain for Scenario 1 and Scenario 2. If pollutant-outcome pairs with a high confidence level on CRF data are considered (Group $A^{*}$ ), delta-external costs range between $-136,000 € / y$ and $-532,000 € / y$ for Scenario 1 and between $-91,000 € / y$ and $-307,000 € / y$ for Scenario 2. If pollutant-outcome pairs with high and medium confidence levels on CRF data are considered (Group $\mathrm{A}^{*}+$ Group $\mathrm{B}^{*}$ ) delta-external costs range between $-999,000 € / y$ and $-2668,000 € / y$ for Scenario 1 and between $-588,000 € / y$ and $-1563,000 € / y$ 
for Scenario 2. The implementation of both scenarios is thus expected to bring a significant reduction of negative externalities over the studied domain. The results of Scenario 2 indicate that a significant cost reduction may be achieved, not only by working on the improvement of the conversion and emission efficiency of power plants but also by limiting the exposure of citizens to impacts of pollution. It is not possible to obtain the same conclusion if the only difference of pollutant concentrations was considered. Table 4 also shows that the estimated uncertainty associated with the results is high. In fact, maximum and minimum values of a factor differ between 3 and 4 . The difference in the results between high-confidence and medium-confidence pollutant-outcome pairs is instead equal to a factor of around 5. This result confirms that the quantification and minimization of uncertainty remains the main challenge in external health costs modelling $[28,59,60]$.

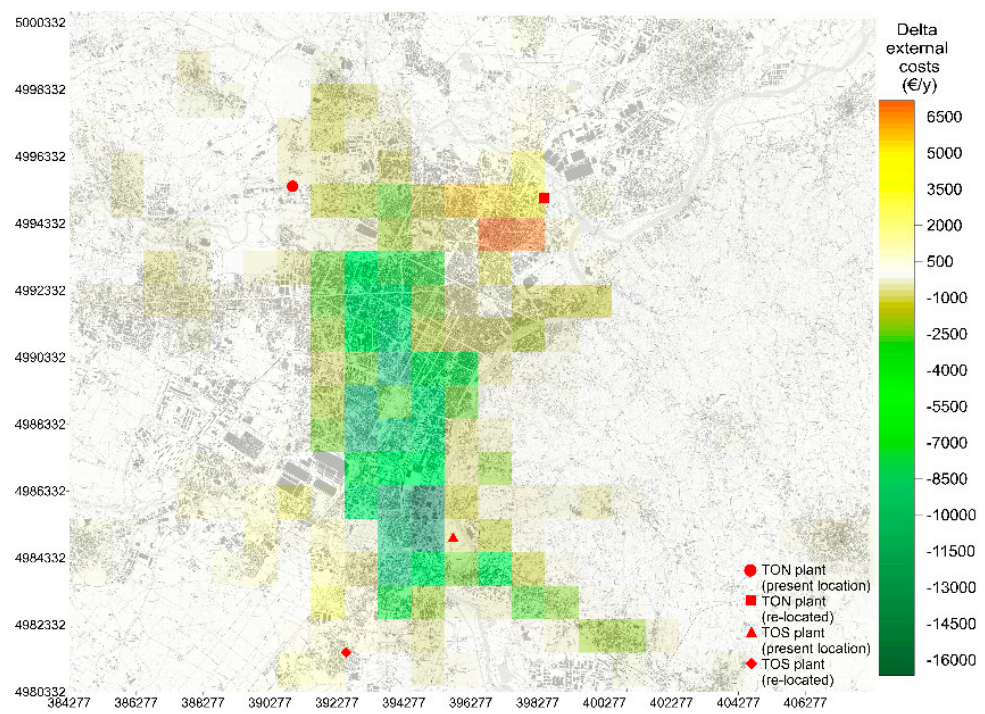

Figure 8. Distribution of delta-external costs between the base case and Scenario 2.

Table 4. Total variation of external costs between the base case and the scenarios considered.

\begin{tabular}{|c|c|c|c|c|c|c|}
\hline \multirow{2}{*}{$\begin{array}{c}\text { Confidence Level on CRF Data } \\
\text { (Setting) }\end{array}$} & \multicolumn{2}{|c|}{$\begin{array}{l}\text { Delta External Costs MEAN } \\
(€ / y)\end{array}$} & \multicolumn{2}{|c|}{$\begin{array}{l}\text { Delta-External Costs } \\
\text { MINIMUM }(€ / y)\end{array}$} & \multicolumn{2}{|c|}{$\begin{array}{l}\text { Delta-External Costs } \\
\text { MAXIMUM }(€ / y)\end{array}$} \\
\hline & $\begin{array}{l}\text { Scenario } \\
\text { 1-Present }\end{array}$ & $\begin{array}{l}\text { Scenario } \\
\text { 2-Present }\end{array}$ & $\begin{array}{l}\text { Scenario } \\
\text { 1-Present }\end{array}$ & $\begin{array}{l}\text { Scenario } \\
\text { 2-Present }\end{array}$ & $\begin{array}{l}\text { Scenario } \\
\text { 1-Present }\end{array}$ & $\begin{array}{l}\text { Scenario } \\
\text { 2-Present }\end{array}$ \\
\hline $\begin{array}{c}\text { High (Group A*) } \\
\text { Medium (Group A* + Group B*) }\end{array}$ & $\begin{array}{c}-365,000 \\
-1,790,700\end{array}$ & $\begin{array}{l}-213,000 \\
1,056,000\end{array}$ & $\begin{array}{l}-532,000 \\
-2,668,400\end{array}$ & $\begin{array}{l}-307,000 \\
-1,563,000\end{array}$ & $\begin{array}{l}-136,000 \\
-999,000\end{array}$ & $\begin{array}{l}-91,000 \\
-588,000\end{array}$ \\
\hline
\end{tabular}

\section{Discussion}

The application of the DIDEM model to the case study of Turin reported the preliminary evaluation of possible actions and measures to be implemented for air quality improvement. In the specific case, Turin's DH system was considered. The extension and improvement of DH networks in urban areas is considered a high-priority measure in the present draft of Piemonte's AQP. In this study, different scenarios of power plant management were simulated and evaluated on the basis of the IPA. Total health external costs variation was used as an indicator of effectiveness. The use of high-resolution tools based on detailed air quality modelling, like DIDEM, allowed for a precise definition of the spatial distribution of costs over the modelling domain. This analysis resulted effectively in defining the solution with the lowest generation of health externalities.

Several studies are reported in bibliography, where external costs are calculated with the use of modelling tools. To date, this methodology has still not been widely extended to an intersectoral set of actions and measures. A single experience in this sense is reported by Silveira et al. [18], who applied the IPA to the AQP process in the Grande Porto urban area (Portugal). In this study, the following emission abatement measures were considered: (i) replacing 10\% of light vehicles below Euro 3 by hybrid vehicles 
(HYB), (ii) replacing/reconverting 50\% of fireplaces (FIR), (iii) introducing a Low-Emission Zone in the city of Porto (LEZ), and iv) implementing particle emission reduction technologies in industrial combustion and production processes (IND). The Air Pollution Model (TAPM, [61]) was used, with a $1 \mathrm{~km}^{2}$ of spatial resolution and $1 \mathrm{~h}$ of temporal resolution. The abatement scenario combining all measures leads to an expected health benefit of 8.8 million $€$ /year. Other previous studies focused on single mitigation measures, in particular in the energy sector. Bachmann and Van der Kamp [62] used the EcoSenseWeb tool [31] to evaluate a $\mathrm{DeNO}_{\mathbf{x}}$ retrofit at a coal-fired power plant. The external costs of the plant without a $\mathrm{DeNO}_{\mathrm{x}}$ ranged between $2.30 \epsilon_{\text {cent }} / \mathrm{kWh}_{\mathrm{e}}$ and $4.15 \epsilon_{\text {cent }} / \mathrm{kWh}$. The installation of a DeNO $\mathrm{x}_{\mathrm{x}}$ provided a reduction of costs between $17 \%$ and $33 \%$, depending on the supposed location of the plant. Van der Kamp and Bachmann [12] applied four different IPA methodologies (ExternE, [11]; EcoSenseWeb, [31]; New Elements for the Assessment of External Costs from Energy Technologies-NewExt2004, [63]; New Energy Externalities Developments for Sustainability-NEEDS2009, [64]) on a $600 \mathrm{MW}_{\mathbf{e}}$ pulverized coal combustion unit located in Western France. The results ranged between $1.77 \epsilon_{\text {cent2000 }} / \mathrm{kWh}_{\mathbf{e}}$ and 5.21 $€_{\text {cent2000 }} / \mathrm{kWh}_{\mathrm{e}}$, depending on the selected model and procedure.

In principle, the tools and procedures applied to the present case study could be extended and adapted to evaluate other interventions reported in Piemonte's AQP. Some useful application could be, for example, the evaluation of emission reduction strategies in the mobility sector, or support for the definition of emission reduction targets in residential buildings. Expanding the perspective, the methodology could be applied more extensively, to evaluate and assign a priority to the different actions reported in local AQPs. Such a methodology could further be progressively integrated into the general IAM framework supporting the air quality planning process.

The concepts developed within the HIA methods are still under debate among the scientific community. IPA modelling and the use of damage costs have generated controversy, due to the inherent uncertainties in the whole process $[59,60,65,66]$. Beside the air modelling approach, the main source of uncertainty in modelling external health impacts and costs is related to the simulation of exposure-response-monetary evaluation steps. The main sources of errors in these steps are the definition of the CRFs, the estimation of exposure, the extrapolation of baseline mortality and morbidity rates and the definition of monetary values. Estimating total uncertainty is an essential element of the integrated assessment process. In order to assess the total uncertainty of an integrated system, the uncertainty related to the different modelling components of the system (meteorological modelling, air quality modelling, exposure modelling, cost-benefit modelling) has to be quantified separately [67]. Possible ways to explore the uncertainties in the context of specific decisions is to carry out sensitivity and comparative analyses. Few studies in bibliography reported on uncertainty/sensitivity analysis in the IAM system $[68,69]$. More research efforts are thus needed to address the following issues:

- Shifting from "static" exposure models (i.e., static maps of population) to "dynamic" exposure models (i.e., considering hour-by-hour where the population is living/working, depending on age, gender, activity);

- Defining higher spatial and temporal distribution of pollutant concentrations;

- Performing local individual and population exposure studies to better link air quality data, health effects and monetary valuation;

- $\quad$ Elaborating procedures to evaluate and standardize HIA results.

Regarding the monetary valuation of health impacts, some criticism was addressed to the methodologies underlying the IPA [70]. The IPA is based on the willingness to pay (WTP) and willingness to accept (WTA) principles. Although WTP and WTA measures are a well-established concept, research efforts are still needed to define the best estimate of their measure [71]. Finally, another important aspect is related to the ability of modelling tools to implement the available data and the regional/local specificities that characterize the air quality planning process. In this view, different models are being designed to approach different spatial scales (from regional, to local, to 
street level). In the future, these different scales shall be built together, to integrate a "scalable analysis" in the IAM process, depending on the specific objectives and needs.

\section{Conclusions}

The shift towards a circular and sustainable economy requires a radical and fast change of the technologic and social structure of national and local communities. Environmental negative externalities represent a barrier to sustainable development, as they imply an inefficient allocation of resources and economic losses to society. Environmental externalities are presently generated at all scales: globally, with the contribution of anthropic activities to the greenhouse effect and climate change; and locally, with the emission of pollutants affecting human health and ecosystems. The estimation and evaluation of negative externalities must thus be implemented in the decision-making process with the objective of their minimization.

This study considered the health damage externalities associated with air pollution, with a particular focus on the local/urban scale. A state of the art of the European Region was reported, focusing on the current methodologies and tools supporting air quality planning policies. The case study of the Piemonte region in Italy was then considered. A scenario analysis was performed with the advice of the DIDEM model. External health costs were quantified to evaluate different management solutions of the DH system of Turin, Piemonte's capital town.

Recalling the three questions reported in Chapter 1, some considerations may be obtained in conclusion of the present study. The first question concerned the level of consideration of health externalities within the decision-making process. The analysis of the actual state and structure of local air quality planning in the European region showed that, in general, AQPs have successfully addressed air quality assessment issues including dispersion and chemistry, but have not yet been fully integrated with other health indicators. The positive aspect is that, among these implemented HIA, most plans use the current state of the art methodology. The second question concerned how HIA can be effectively integrated into the AQP process. In this study, the use of specifically-designed, comparison-based modelling tools based on the IPA provided valuable support for: (i) the screening and analysis of qualitative and quantitative site-specific constraining factors regulating the considered plan measure, and (ii) the selection of the most environmentally and socially sustainable alternative of implementation. The discussion of the results confirmed that the reported methodology should be extended and adapted to other measures and actions of Piemonte's AQP, as well as other local planning schemes across Europe. Extending the scope of analysis, more efforts will be needed for a broader implementation of HIA and externalities tools into the general IAM framework supporting the air quality planning process. In fact, it is known that the design of planning schemes for air quality improvement and emission reduction is a complicated process based on a multi-disciplinary and multi-stakeholder approach. Such a process requires an assessment structure able to consider a long-term perspective and the continuous evolution of society and technology. IPA-based tools must thus be developed to fit into this extended assessment structure.

The third question concerned the use of externalities as an efficient indicator for the evaluation of alternative scenarios. IPA modelling and the use of damage costs are currently objects of criticism, due to the inherent uncertainties in the whole process. Nevertheless, in the future, the air quality planning process will become more and more integrated with other existing economic and development plans. In addition, non-technical measures will become increasingly important for the mitigation of both air quality and climate change. Policy development will require analytical tools which are capable of dealing with a wider range of measures and changes. In this perspective, air pollution externalities may become a clear and direct indicator supporting the effective implementation of planning actions.

Author Contributions: Conceptualization, M.R, D.P. and M.Z.; Methodology, M.R, D.P. and M.Z.; Software, M.R; Validation, M.R, D.P. and M.Z.; Formal Analysis, M.R, D.P. and M.Z.; Investigation, M.R, D.P. and M.Z.; Resources, D.P. and M.Z.; Data Curation, M.R, D.P. and M.Z.; Writing-Original Draft Preparation, M.R.; Writing-Review \& 
Editing, D.P. and M.Z.; Visualization, D.P. and M.Z.; Supervision, D.P. and M.Z.; Project Administration, D.P. and M.Z.; Funding Acquisition, M.Z.

Funding: This research received no external funding.

Acknowledgments: The authors acknowledge Piemonte's Regional Environmental Agency (ARPA Piemonte) for the data provided.

Conflicts of Interest: The authors declare no conflict of interest.

\section{References}

1. Andersen, M.S. An introductory note on the environmental economics of the circular economy. Sustain. Sci. 2007, 2, 133-140. [CrossRef]

2. Pigou, A.C. The Economics of Welfare; Macmillan: London, UK, 1920.

3. Samet, J.; Krewski, D. Health effects associated with exposure to ambient air pollution. J. Toxicol. Environ. Health Part A 2007, 70, 227-242. [CrossRef] [PubMed]

4. Costa, S.; Ferreira, J.; Silveira, C.; Costa, C.; Lopes, D.; Relvas, R.; Borrego, C.; Roebeling, P.; Miranda, A.I.; Teixeira, J. Integrating health on air quality assessment-Review report on health risks of two major European outdoor air pollutants: PM and $\mathrm{NO}_{2}$. J. Toxicol. Environ. Health Part B 2014, 17, 307-340. [CrossRef]

5. European Community. Directive 2009/28/EC. On the promotion of the use of energy from renewable sources and amending and subsequently repealing Directives 2001/77/EC and 2003/30/EC.2009.04.23. Off. J. EUL 2009, 140, 16-62.

6. Santoyo-Castelazo, E.; Azapagic, A. Sustainability assessment of energy systems: Integrating environmental, economic and social aspects. J. Clean. Prod. 2014, 80, 119-138. [CrossRef]

7. Panepinto, D.; Brizio, E.; Genon, G. Atmospheric pollutants and air quality effects: Limitation costs and environmental advantages (a cost-benefit approach). Clean Technol. Environ. Policy 2014, 16, 1805-1813. [CrossRef]

8. Thunis, P.; Rouil, L.; Cuvelier, C.; Stern, R.; Kerschbaumer, A.; Bessagnet, B.; Schaap, M.; Builtjes, P.; Tarrason, L.; Douros, J.; et al. Analysis of model responses to emission-reduction scenarios within the CityDelta project. Atmos. Environ. 2007, 41, 208-220. [CrossRef]

9. Thunis, P.; Miranda, A.; Baldasano, J.M.; Blond, N.; Douros, J.; Graff, A.; Janssen, S.; Rezler, J.; Karvosenoja, N.; Maffeis, G.; et al. Overview of current regional and local scale air quality modelling practices: Assessment and planning tools in the EU. Environ. Sci. Policy 2016, 65, 13-21. [CrossRef]

10. Mediavilla-Sahagun, A.; ApSimon, H. Urban scale integrated assessment of options to reduce $\mathrm{PM}_{10}$ in London towards attainment of air quality objectives. Atmos. Environ. 2013, 37, 4651-4665. [CrossRef]

11. University of Stuttgart. Institute of Energy Economics and the Rational Use of Energy (IER). ExternE-External Costs of Energy. Available online: http:/ / www.externe.info/ (accessed on 6 December 2018).

12. van der Kamp, J.; Bachmann, T.M. Health-related external cost assessment in Europe: Methodological developments from ExternE to the 2013 Clean Air Policy Package. Environ. Sci. Technol. 2015, 49, 2929-2938. [CrossRef]

13. Hammitt, J.K.; Haninger, K. Valuing nonfatal health risk as a function of illness severity and duration: Benefit transfer using QALYs. J. Environ. Econ. Manag. 2017, 82, 17-38. [CrossRef]

14. Bachmann, T.M.; van der Kamp, J. Expressing air pollution-induced health-related externalities in physical terms with the help of DALYs. Environ. Int. 2017, 103, 39-50. [CrossRef] [PubMed]

15. Gold, M.R.; Stevenson, D.; Fryback, D.G. HALYS and QALYS and DALYS, oh my: Similarities and differences in summary measures of population health. Annu. Rev. Public Health 2002, 23, 115-134. [CrossRef] [PubMed]

16. Miranda, A.I.; Ferreira, J.; Silveira, C.; Relvas, H.; Duque, L.; Roebeling, P.; Lopes, M.; Costa, S.; Monteiro, A.; Gama, C.; et al. A cost-efficiency and health benefit approach to improve urban air quality. Sci. Total Environ. 2016, 569-570, 342-351. [CrossRef] [PubMed]

17. Nieuwenhuijsen, M.J.; Khreis, H.; Verlinghieri, E.; Mueller, N.; Rojas-Rueda, D. Participatory quantitative health impact assessment of urban and transport planning in cities: A review and research needs. Environ. Int. 2017, 103, 61-72. [CrossRef]

18. Silveira, C.; Roebeling, P.; Lopes, M.; Ferreira, J.; Costa, S.; Teixeira, J.P.; Borrego, C.; Miranda, A.I. Assessment of health benefits related to air quality improvement strategies in urban areas: An Impact Pathway Approach. J. Environ. Manag. 2016, 183, 694-702. [CrossRef] [PubMed] 
19. APPRAISAL EU FP7 Project. Available online: http:/ / www.appraisal-fp7.eu (accessed on 6 December 2018).

20. Carnevale, C.; Finzi, G.; Pisoni, E.; Volta, M.; Guariso, G.; Gianfreda, R.; Maffeis, G.; Thunis, P.; White, L.; Triacchini, G. An integrated assessment tool to define effective air quality policies at regional scale. Environ. Model. Softw. 2012, 38, 306-315. [CrossRef]

21. Vautard, R.; Builtjes, P.; Thunis, P.; Cuvelier, C.; Bedogni, M.; Bessagnet, B.; Honoré, C.; Moussiopoulos, N.; Pirovano, G.; Schaap, M.; et al. Evaluation and intercomparison of ozone and $\mathrm{PM}_{10}$ simulations by several chemistry transport models over four European cities within the CityDelta project. Atmos. Environ. 2007, 41, 173-188. [CrossRef]

22. Amann, M.; Bertok, I.; Borken-Kleefeld, J.; Cofala, J.; Heyes, C.; Höglund-Isaksson, L.; Klimont, Z.; Nguyen, B.; Posch, M.; Rafaj, P.; et al. Cost-effective control of air quality and greenhouse gases in Europe: Modelling and policy applications. Environ. Model. Softw. 2011, 26, 1489-1501. [CrossRef]

23. Guariso, G.; Pirovano, G.; Volta, M. Multi-objective analysis of ground-level ozone concentration control. J. Environ. Manag. 2004, 71, 25-33. [CrossRef]

24. Oxley, T.; ApSimon, H.; Dore, A.; Sutton, M.; Hall, J.; Heywood, E.; Gonzales del Campo, T.; Warren, R. The UK Integrated Assessment Model, UKIAM: A national scale approach to the analysis of strategies for abatement of atmospheric pollutants under the Convention on Long-Range Transboundary Air Pollution. Integr. Assess. 2003, 4, 236-249. [CrossRef]

25. Zachary, D.S.; Drouet, L.; Leopold, U.; Aleluia Reis, L. Trade-offs between energy cost and health impact in a regional coupled energy-air quality model: The LEAQ model. Environ. Res. Lett. 2011, 6, 024021. [CrossRef]

26. D'Elia, I.; Bencardino, M.; Ciancarella, L.; Contaldi, M.; Vialetto, G. Technical and Non-Technical Measures for air pollution emission reduction: The integrated assessment of the regional Air Quality Management Plans through the Italian national model. Atmos. Environ. 2009, 43, 6182-6189. [CrossRef]

27. EEA, European Environmental Agency. Air Implementation Pilot: Lessons Learnt from the Implementation of Air Quality Legislation at Urban Level; European Environment Agency: Luxembourg, 2013; ISSN 1725-9177.

28. Anenberg, S.C.; Belova, A.; Bramdt, J.; Fann, N.; Greco, S.; Guttikunda, S.; Heroux, M.E.; Hurley, F.; Krzyzanowski, M.; Medina, S.; et al. Survey of Ambient Air Pollution Health Risk Assessment Tools. Risk Anal. 2016, 36, 1718-1736. [CrossRef] [PubMed]

29. Ravina, M.; Panepinto, D.; Zanetti, M.C. DIDEM-An integrated model for comparative health damage costs calculation of air pollution. Atmos. Environ. 2018, 173, 81-95. [CrossRef]

30. Preiss, P.; Klotz, V. EcoSenseWeb V1.3 User's Manual and Description of Updated and Extended Draft Tools for the Detailed Site Dependent Assessment of External Sosts; Institute of Energy Economics and the Rational Use of Energy (IER), University of Stuttgart: Stuttgart, Germany, 2008.

31. IER Institute of Energy Economics and the Rational Use of Energy. EcoSense 4.0 User's Manual; University of Stuttgart: Stuttgart, Germany, 2004.

32. Brandt, J.; Silver, J.D.; Christensen, J.H.; Andersen, M.S.; Bønløkke, J.H.; Sigsgaard, T.; Geels, C.; Gross, A.; Hansen, A.B.; Hansen, K.M.; et al. Contribution from the ten major emission sectors in Europe and Denmark to the health-cost externalities of air pollution using the EVA model system-An integrated modelling approach. Atmos. Chem. Phys. 2013, 13, 7725-7746. [CrossRef]

33. Mediavilla-Sahagun, A.; Apsimon, H.; Warren, R.F. Integrated Assessment of Abatement Strategies to Improve Air Quality in Urban Environments, the USIAM Model. Water Air Soil Pollut. Focus 2002, 5, 689-701. [CrossRef]

34. Mensink, C.; De Ridder, K.; Lewyckyj, N.; Lefebre, F.; Janssen, L.; Cornelis, J.; Adriaensen, S.; Ruts, M. AURORA: An Air Quality Model for Urban Regions Using an Optimal Resolution Approach. In Development and Application of Computer Techniques to Environmental Studies; Brebbia, C.A., Zannetti, P., Eds.; WIT Press: Southampton, UK, 2002; ISBN 1-85312-909-7.

35. Derwent, R.G.; Dollard, G.J.; Metcalfe, S.E. On the nitrogen budget for the United Kingdom and north-west Europe. Q. J. R. Meteorol. Soc. 1988, 114, 1127-1152. [CrossRef]

36. Olesen, H.R.; Løfstrøm, P.; Berkowicz, R.; Jensen, A.B. An Improved Dispersion Model for Regulatory Use-The OML Model. In Air Pollution Modeling and Its Application IX. NATO Challenges of Modern Society; Springer: Boston, MA, USA, 1992; pp. 29-38.

37. Christensen, J.H. The Danish Eulerian Hemispheric Model—A three-dimensional air pollution model used for the Arctic. Atmos. Environ. 1997, 31, 4169-4191. [CrossRef] 
38. Silveira, C.; Lopes, M.; Roebeling, P.; Ferreira, J.; Costa, S.; Teixeira, J.P.; Borrego, C.; Miranda, A.I. Economic evaluation of air pollution impacts on human health: An overview of applied methodologies. WIT Trans. Ecol. Environ. 2015, 198, 181-192. [CrossRef]

39. Carnevale, C.; Ferrari, F.; Gianfreda, G.; Guariso, G.; Janssen, S.; Maffeis, G.; Miranda, A.I.; Pederzoli, A.; Relvas, H.; Thunis, P. Two Illustrative Examples: Brussels and Porto. In Air Quality Integrated Assessment: A European Perspective; Volta, M., Guariso, G., Eds.; Springer International Publishing AG: Basel, Switzerland, 2017.

40. Piemonte's Regional Agency for the Environmental Protection. A Look to the Air. Annual Report on Data Monitored by the Regional Air Quality Network; Technical Report; Piemonte Region: Turin, Italy, 2012. (In Italian)

41. Piemonte's Regional Emission Inventory. Available online: http://www.sistemapiemonte.it/fedwinemar/ elenco.jsp (accessed on 6 December 2018).

42. The Climate Group. Under2Coalition. Available online: https://www.under2coalition.org/ (accessed on 6 December 2018).

43. Piemonte's Regional Air Quality Plan (PRQA). Available online: http://www.regione.piemonte.it/ambiente/ aria/piano_regionale.htm (accessed on 6 December 2018). (In Italian)

44. GAINS, Greenhouse Gas-Air Pollution Interactions and Synergies Model. Available online: http:/ / www. iiasa.ac.at/web/home/research/researchPrograms/air/GAINS.html (accessed on 6 December 2018).

45. Aria Technologies Company. Available online: http://www.aria.fr/ (accessed on 6 December 2018).

46. Arianet Company. Available online: http://www.aria-net.it/ (accessed on 6 December 2018).

47. Dunker, A.M.; Yarwood, G.; Ortmann, J.; Wilson, G.W. The Decoupled Direct Method for Sensitivity Analysis in a Three-Dimensional Air Quality Model-Implementation, Accuracy, and Efficiency. Environ. Sci. Technol. 2002, 36, 2965-2976. [CrossRef] [PubMed]

48. VIIAS Project (Valutazione Integrata dell'Impatto dell'Inquinamento Atmosferico sull'Ambiente e sulla Salute). Available online: https:/ / www.viias.it/ (accessed on 6 December 2018). (In Italian)

49. Liu, H.Y.; Kobernus, M.; Fredriksen, M.; Golumbic, Y.; Robinson, J. A Toolbox for Understanding and Implementing a Citizens' Observatory on Air Monitoring. In Multimedia Tools and Applications for Environmental $\mathcal{E}$ Biodiversity Informatics; Joly, A., Vrochidis, S., Karatzas, K., Karppinen, A., Bonnet, P., Eds.; Springer Nature AG: Basel, Switzerland, 2018.

50. Lund, R.; Van Mathiesen, B. Large combined heat and power plants in sustainable energy systems. Appl. Energy 2015, 142, 389-395. [CrossRef]

51. Werner, S. International review of district heating and cooling. Energy 2017, 137, 617-631. [CrossRef]

52. Ravina, M.; Panepinto, D.; Zanetti, M.C.; Genon, G. Environmental analysis of a potential district heating network powered by a large-scale cogeneration plant. Environ. Sci. Pollut. Int. 2017, 24, 13424-13436. [CrossRef] [PubMed]

53. JRC, European Joint Research Centre. Best Available Techniques (BAT) Reference Document for Large Combustion Plants; JRC Science for Policy Report; European Union: Seville, Spain, 2017.

54. EPA, United States Environmental Protection Agency. Air Quality Dispersion Modelling-Preferred and Recommended Models. Available online: https:/ / www.epa.gov/scram/air-quality-dispersion-modelingpreferred-and-recommended-models (accessed on 6 December 2018).

55. WHO, World Health Organization. Health Risks of Air Pollution in Europe-HRAPIE Project Recommendations for Concentration-Response Functions for Cost-Benefit Analysis of Particulate Matter, Ozone and Nitrogen Dioxide; World Health Organization, Regional Office for Europe: Copenaghen, Denmark, 2013; p. 54.

56. WHO, World Health Organization. Review of Evidence on Health Aspects of Air Pollution-REVIHAAP Project; Technical Report; The WHO European Centre for Environment and Health: Bonn, Germany, 2013; p. 302.

57. Holland, M. Implementation of the HRAPIE Recommendations for European Air Pollution CBA Work; Report; European Union: Edinburgh, UK, 2014.

58. Ravina, M.; Panepinto, D.; Zanetti, M.C. A dispersion and externalities model supporting energy planning: Development and case study. WIT Trans. Ecol. Environ. 2018, 230, 153-164. [CrossRef]

59. Bridges, A.; Felder, F.A.; McKelvey, K.; Niyogi, I. Uncertainty in energy planning: Estimating the health impacts of air pollution from fossil fuel electricity generation. Energy Res. Soc. Sci. 2015, 6, 74-77. [CrossRef]

60. Lamson, A. Influence Analysis in Support of Characterizing Uncertainty in Human Health Benefits Analysis; U.S. Environmental Protection Agency, Office of Air Quality Planning and Standards (OAQPS), Air Benefit and Cost Group (ABCG): Research Triangle Park, NC, USA, 2009. 
61. Hurley, P.; Physick, W.; Luhar, K. TAPM: A practical approach to prognostic meteorological and air pollution modelling. Environ. Model. Softw. 2005, 20, 737-752. [CrossRef]

62. Bachmann, T.M.; van der Kamp, J. Environmental cost-benefit analysis and the EU (European Union) Industrial Emissions Directive: Exploring the societal efficiency of a DeNOx retrofit at a coal-fired power plant. Energy 2014, 68, 125-139. [CrossRef]

63. European Commission. New Elements for the Assessment of External Costs from Energy Technologies (NewExt)—Final Report to the European Commission, DG Research, Technological Development and Demonstration (RTD); European Commission: Brussels, Belgium, 2004; p. 333.

64. NEEDS2009, New Energy Externalities Developments for Sustainability. Available online: http://esuservices.ch/data/needs/ (accessed on 3 January 2019).

65. Cropper, M.; Khanna, L. How Should the World Bank Estimate Air Pollution Damages? Discussion Paper; Resources for the Future: Washington, DC, USA, 2014.

66. Sonnemann, G.W.; Pla, Y.; Schuhmacher, M.; Castells, F. Framework for the uncertainty assessment in the impact pathway analysis with an application on a local scale in Spain. Environ. Int. 2002, 28, 9-18. [CrossRef]

67. Belis, C.; Blond, N.; Bouland, C.; Carnevale, C.; Clappier, A.; Douros, J.; Fragkou, E.; Guariso, G.; Miranda, A.I.; Nahorski, Z.; et al. Strengths and Weaknesses of the Current EU Situation. In Air Quality Integrated Assessment: A European Perspective; Volta, M., Guariso, G., Eds.; Springer International Publishing AG: Basel, Switzerland, 2017.

68. Uusitalo, L.; Lehikoinen, A.; Helle, I.; Myrberg, K. An overview of methods to evaluate uncertainty of deterministic model in decision support. Environ. Model. Softw. 2015, 63, 24-31. [CrossRef]

69. Oxley, T.; ApSimon, H. Space, time and nesting integrated assessment models. Environ. Model. Softw. 2007, 22, 1732-1749. [CrossRef]

70. Hammitt, J.K. Admissible utility functions for health, longevity, and wealth: Integrating monetary and life-year measures. J. Risk Uncertain. 2013, 47, 311-325. [CrossRef]

71. Chestnut, L.G.; De Civita, P. Policy Research. Economic Valuation of Mortality Risk Reduction: Review and Recommendations for Policy and Regulatory Analysis; PRI Project, Regulatory Strategy; Research Paper; Government of Canada: Ottawa, Canada, 2009. 